\title{
O PROBLEMA DA CULTURA: INVESTIGAÇÃO SOBRE O ENSINO DE FILOSOFIA COMO ENGAJAMENTO POLIITICO
}

\author{
Carlos Miguel da Silva Souza* \\ Jean Mac Cole Tavares Santos**
}

\begin{abstract}
Resumo: Nesta pesquisa bibliográfica buscamos interpretar a prática docente em filosofia em Mossoró-RN como prática política. O engajamento político como prática docente em filosofia é compreendido como uma alternativa para o problema da cultura. Para tanto, partindo de uma perspectiva pósestrutural, nos aproximamos dos conceitos de formação e cultura da Paideia na primeira parte, prosseguindo com o acompanhamento da educação jesuíta no Brasil na segunda, desembocando nos dois últimos pontos: 'a filosofia e seu ensino em Mossoró-RN', com um diálogo das reflexões dos depoentes e 'o ensino de filosofia como engajamento político', onde discutimos a docência em filosofia como prática política.
\end{abstract}

Palavras-chave: Ensino; Filosofia; Engajamento; Cultura; Política

Resumen: A través de esta investigación bibliográfica buscamos interpretar la práctica docente en filosofía realizada en Mossoró-RN como una práctica política. El compromiso político -como práctica docente en filosofía- es asumido como una alternativa al problema de la cultura. Para ello, ubicándonos en una perspectiva post-estructuralista, en la primera parte abordamos los conceptos de formación y cultura desde la Paideia, en la segunda parte realizamos una revisión de la educación jesuita en Brasil, y terminamos con los siguientes dos últimos puntos: (1) "La Filosofía y su Enseñanza en Mossoró -RN", dialogando con las reflexiones de los expositores y (2) "La Enseñanza de la Filosofía como Compromiso Político", donde discutimos la enseñanza de la filosofía como práctica política.

Palabras Claves: Enseñanza; Filosofía; Compromiso Político; Cultura; Política

\section{Introdução}

A pesquisa de cunho bibliográficodocumental a seguir explora o panorama formativo do Ocidente em suas linhas gerais para compreender o problema da cultura: a questão da articulação entre ensino técnico e formação humana. Depois de incursionarmos pela Antiguidade Grega, discutiremos a formação da brasilidade pelos jesuítas no Brasil Colônia e o desenvolvimento do ensino de filosofia. Nos últimos momentos, dialogaremos sobre o exercício docente em filo-

\footnotetext{
* Mestrando do Programa Interinstitucional de PósGraduação em Ensino (POSENSINO/UERN/UFERSA/IFRN).

E-mail: miguelmaggotbone@gmail.com

** Doutorado em Educação pela Universidade Federal da Paraíba. Coordenador do POSENSINO da Universidade do Estado do Rio Grande do Norte.
}

sofia em Mossoró-RN para compreender sua relação com a prática política. Nossa proposta é analisar as práticas educativas de filosofia em Mossoró-RN como ação política.

A necessidade de pesquisas acerca da prática política como alternativa para o problema da cultura acentua-se em uma época onde o cerceamento político de professores se mostra cada vez mais radical. Cogitar possibilidades, exercitar as vias de interferência na construção discursiva hegemônica de cancelamento das manifestações de diferença são maneiras de oferecer resistências ao status-quo da política nacional, seja ela de natureza institucional ou não. Por descentrar os sujeitos do fazer político, por cultivar significantes vazios e permitir as releituras e reinterpretações discursivas, optamos

SOUZA, Carlos Miguel da Silva; SANTOS, Jean Mac Cole Tavares. O problema da cultura: investigação sobre o ensino de filosofia como engajamento político. Revista Sul-Americana de Filosofia e Educação. Número 32/33: nov. 2019 - out. 2020, p. 20-29. DOI: https://doi.org/10.26512/resafe.v1i32/33.35103 
pela abordagem pós-estrutural como arcabouço filosófico para essa empreitada.

Indo além da visão crítica da educação, o pós-estruturalismo põe em xeque qualquer tentativa de definição última das coisas. Para desconstruir a opinião de que tudo é política, compreendemos esta enquanto decisão em terreno indecidível. A escolha onde não é possível escolher. Uma ação só é política quando pautada na nãoobrigatoriedade, quando nasce da contingência, em suma, quando há engajamento. Talvez seja tempo de esboçarmos o fazer docente - sobretudo em filosofia - como um exercício radicalmente político de provocação da livre manifestação da diferença.

\section{Tradição e história}

Habitualmente compreendemos com a palavra "cultura" o conjunto das manifestações produzidas pelos seres humanos. Distante de um rigor interpretativo, esse "[...] espaço em que se desenrola a atividade espiritual e criadora do homem" (Heidegger, 2012, p. 39) é confundido com o modo de ser mais próprio deste ente. Hipotetizando esta opinião, temos que pensar se, dentro das manifestações/produções humanas em nossa época insere-se a ciência como um tipo de criação cultural, e se esta perspectiva pode nos esclarecer algo sobre o fazer docente. Mas, por que isso importa?

A ciência hoje não se apresenta como mais uma produção dentre outras às quais nos debruçamos, mas é o horizonte mesmo onde nos movemos e como que o alicerce das criações fundamentadas em um sentido que seja evidente por si próprio, válido. Os negócios, a política institucional, a saúde, a alimentação, e sobretudo o elemento que permite tudo isso - o ensino, estão radicalmente permeados por e se desdobram de maneira científica. Essa profunda dependência a um savoir-faire (propostas como a BNCC, os PCN, e seus parâmetros técnico- morais que dispõem a própria tessitura dessas políticas, por exemplo ${ }^{3}$ ) nos inquieta sobre os modos como nos fazemos em nossa época. Não é de nosso interesse uma descrição historiográfica da ciência de Aristóteles à Descartes e à revolução liberal das máquinas. Entrevemos tão somente propor uma reflexão sobre os fundamentos de por que fazemos o que fazemos no campo demasiado humano do ensino e, em nossa época de crise da educação brasileira, o que a apropriação da nossa tradição ocidental pode oferecer em questão de criação de perspectivas de transformação, reinterpretação do estado de coisas, superação dessa crise em direção à uma mais profunda.

A rigor, existem dois significados de 'cultura': a interminável formação do ser humano, seu refinamento e crescimento; o outro, antropológico, diz o resultado dessa formação, a transmissão dos modos de ser alcançados pelo processo formativo, as maneiras de pensar e agir que podemos chamar também de civilização. Observaremos brevemente, mas não sem profundidade essas duas compreensões e seu imbricamento comum. $\mathrm{O}$ primeiro conceito de cultura remete à origem do que chamamos Ocidente: a Antiguidade Grega. Uma das obras mais profundas e extensas sobre a formação do espírito grego é a Paideia do filólogo alemão Werner Jaeger (2013). No início deste trabalho encontra-se a polêmica afirmação de que "A história da cultura começa com os gregos" (JAEGER, 2013, p. 5). A análise de tal sentença é capaz de nos oferecer uma aproximação do que é o sentido de uma tradi-

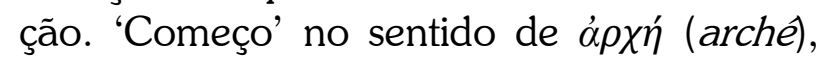
não significa início temporal, ponto de partida; antes, se refere à origem, fonte espiritual, princípio ao qual retomamos sempre que se faz necessário buscar orientações. "É este o motivo por que, no decurso da nossa histó-

\footnotetext{
${ }^{3}$ Ver. PERONI et. al. (2019)
} 
ria, voltamos constantemente à Grécia." (JAEGER, 2013, p. 5).

História, no sentido apresentado por Heródoto, é vista como a "[...] exploração de mundos estranhos, singulares e misteriosos." (JAEGER, 2013, p. 6). Longe de ser a cronologia narrada dos acontecimentos, é o sentimento de pertença de um povo a um destino comum. A apreciação fenomênica de um sentido geral do qual partilha um povo em uma época; a história

[...] se fundamenta numa união espiritual viva $e$ ativa e na comunidade de um destino, quer seja o do próprio povo, quer o de um grupo de povos estreitamente unidos. Só nesta espécie de história se tem uma íntima compreensão e contato criador entre uns e outros. (JAEGER, 2013, p. 6)

A cultura, por sua vez, não pode ser compreendida aqui em seu sentido antropológico. Isso porque as compreensões antropológicas e psicológicas se pautam em uma postura positiva e centrada de igualdade que desembocam inevitavelmente em um equívoco histórico. Não precisaremos entrar em exemplos específicos se observarmos a base da própria linguagem na qual se edifica toda ciência; o horizonte de disponibilidade do discurso da tradição: a organização da linguagem. Em Gramatologia (2017, p. 22), Derrida nos diz que a linguagem é metafísica, o é por estabelecer a dualidade significado/significante, sendo o elemento 'sensível' (significado) privilegiado, em detrimento ao significante (inteligível). Esta compreensão metafísica da linguagem chamada logocentrismo dispõe, assim, uma unidade fala/sentido no campo da linguagem: a fala traz o significado para a presença. Sobretudo a linguagem científica, por residir no interior dessa metafísica, estipula, classifica, outorga $e$ assim justifica a si própria enquanto maisque-discurso ao autorreferenciar-se no mé- todo (POPPER, 2013, p. 41; DESCARTES, 1996, p. 26); um processo que demonstra já não uma irregularidade epistemológica das ciências, mas uma contingência constitutiva de seu alicerce interpretativo.

Seguir uma interpretação psicológica ou antropológica da cultura é estar emaranhado na tessitura de sua metafísica. Assim, a cultura aparece na Antiguidade como a totalidade da obra criativa grega, o topo do desenvolvimento de sua inteligência. Aquilo que é cultivado e venerado é a própria condição fecunda do povo, seus modos de ser $e$ idiossincrasias, e "[...] o que hoje denominamos cultura não passa de um produto deteriorado, derradeira metamorfose do conceito grego originário." (JAEGER, 2013, p.8). Percebemos então que a sentença 'a história da cultura começa com os gregos' é antes de uma assertiva desmedida, uma formulação composta por questões. O princípio do qual deriva todo o crescimento espiritual dos povos fundamentais do Ocidente é o próprio devir da vida enquanto energia. $\mathrm{O}$ sentimento de participação da vida comum, da comunhão de um destino, provém da interpretação que esses gregos possuíam da própria Natureza: a participação de cada coisa em um todo, pois

\begin{abstract}
Muito antes de o espírito grego ter delineado essa ideia, eles já consideravam as coisas do mundo numa perspectiva tal que nenhuma delas lhes aparecia como parte isolada do resto, mas sempre como um todo ordenado e em conexão viva, na $e$ pela qual tudo ganha posição e sentido. (JAEGER, 2013, p.10)
\end{abstract}

Logo, o elemento propiciador da manutenção, refinamento $e$ aprofundamento da tradição é a educação. Educação como um processo de construção consciente, formação de um ser antropoplástico: este é o mais elevado sentido da palavra. 
A educação grega não é uma soma de técnicas e organizações privadas, orientadas para a formação de uma individualidade perfeita $e$ independente. Isto só aconteceu na época helenística, quando o Estado já havia desaparecido - época da qual deriva em linha reta a pedagogia moderna. (JAEGER, 2013, p. 16)

O segundo sentido de cultura, metafísico, (chamado aqui de antropológico por ser largamente utilizado por estes e por sociólogos) diz dos conjuntos de modos de vida criados/transmitidos por um povo de uma sociedade determinada (RIBEIRO, 2006 , p. 20). Aqui a cultura não é a formação humana do indivíduo, mas a anônima definição institucional/moral desses indivíduos inseridos em um grupo social dado. Possivelmente, esse sentido foi inaugurado por Oswald Spengler em 1918 na sua obra 'A Decadência do Ocidente' (SPENGLER, 2013, p. 147) que apesar de sua compreensão vitalista de sociedade como organismo (uma sociedade nasce, cresce e morre, como um indivíduo), forneceu os fundamentos para observar a cultura da maneira supracitada; sem objetivar uma hierarquia valorativa que orientariam a leitura de sociedades como mais ou menos 'evoluídas'.

Essa definição surge tardiamente, no séc. XX, como manifestação do modo de ser de uma cultura que já não é grega nem cristã. Ela está arvorada no movimento epocal de hiperespecialização dos saberes em uma cultura de massa (ocidental) que se alijou da tarefa de formação espiritual dos seres humanos. Se são as necessidades de um povo que dispõem a maneira como a cultura é desdobrada no tempo, hoje perdeu-se esse sentido próprio do povo $e$ as necessidades dos grupos humanos são construídos segundo a lógica do mercado. $\mathrm{O}$ ensino se define nesse horizonte como imposição dos prérequisitos para o autossustento do status quo a partir da operacionalização dos dispositi- vos da vida pós-moderna. É claro que não se pode viver hoje sem estar submetido às disposições técnicas e suas demandas. Tampouco pode-se também permanecer sob o sufocamento da técnica que alheia cada vez mais o ser humano da humanidade.

Isto nos faz chegar ao problema da cultura: como articular as exigências da técnica, da instrumentalização, sem perder de vista a formação humana (já cultivada uma vez no Ocidente) de maneira que se possa equilibrar o existir humano e o saber científico nessa cultura de massa? O que hoje pode fazer um educador que se dedica à filosofia para permitir essa transformação em seu cotidiano de trabalho? Para aprofundar essas respostas nos aproximaremos de pensadores caros à cultura brasileira para perceber no devir do tempo qual é o nosso momento na educação como gesto político e a possibilidade de um engajamento político rigoroso $e$ coerente do profissional de filosofia.

\section{Educação brasílica e adoecimento ontológi- co}

De acordo com Demerval Saviani, a história da educação no Brasil começa com a chegada de Manuel da Nóbrega e seus subalternos (quatro padres e dois irmãos), pertencentes à ordem dos jesuítas, em 1549 (SAVIANI, 2011, p. 26). Acompanhando as naus europeias em seus propósitos mercantis e de exploração, a intenção da ordem jesuíta nestas terras do Novo Mundo era a ocidentalização dos povos originários denominados pejorativamente de índios (ou gentios). A conquista espiritual dos habitantes originários foi elemento chave para a inserção radical da metafísica dos violadores europeus no interior do território (RIBEIRO, 2015, p. 27). Tais povos espraiavam-se por todo o 'novo' território sem constituir

[...] obviamente, uma nação, porque eles não se sabiam tantos nem tão 
dominadores. Eram tão só, uma miríade de povos tribais, falando línguas do mesmo tronco, dialetos de uma mesma língua, cada um dos quais, ao crescer, se bipartia, fazendo dois povos que começavam a se diferenciar e logo se desconheciam e se hostilizavam. (RIBEIRO, 2015, p. 26)

Essa diferença demográfica, cultural, geográfica, política e linguística entre povos antiquíssimos que cultivavam as florestas dos territórios habitados (como se fossem jardins) há milênios, foi o cenário encontrado pelos colonizadores europeus e onde agora eles teriam de intervir. O cultivo da diferença, manifestada pelos povos originários, de forma harmoniosa ou não é algo impossível de suportar do ponto de vista da metafísica ocidental (calcada na metafísica da identidade) trazida pelos europeus junto a outras doenças contagiosas. A transformação daqueles modos de vida dos 'gentios' semelhantes ao comunismo primitivo em força de trabalho hábil para a extração da riqueza foi a meta particular da ordem dos jesuítas que se dedicavam à domesticação desses povos. 1549 também foi o ano do Regimento de Dom João III, que estabelecia diretrizes a serem observadas na colônia. Entre elas, a catequese, que fora o elemento basilar da tarefa educativa de colonização do Brasil, pois seu caráter pedagógico se mostra

[...] uma vez que os jesuítas consideravam que a primeira alternativa de conversão era o convencimento que implicava práticas pedagógicas institucionais (as escolas) e não institucionais (o exemplo). (SAVIANI, 2011, p. 31)

A ideia motriz era o apagamento das diferenças e imposição da norma, da fé, da servidão aos colonizadores. Não obstante a agudeza intelectual de Nóbrega e sua facção, não existia didática alguma no Ocidente que os auxiliasse na educação (aculturação) dos povos daqui. $\mathrm{O}$ que deste momento em diante se desenvolve é um modo de lidar com os índios e os inserir na Palavra de uma maneira inteiramente inaugural, que chamamos junto com Saviani de pedagogia brasílica. Esta, resume as técnicas utilizadas pelos padres para fazer frente à 'educação' dos povos indígenas que (a exemplo dos Tupinambá) inseriam suas crianças e jovens na cultura de seu povo de maneira espontânea e integral. Fazendo seu ser no diálogo e em práticas divididas em faixas etárias, o jovem da tribo amadurecia suas qualidades e responsabilidades paulatinamente até atingir o grau de transmissão e ensino da essência de sua tribo, transformando-se incessantemente. Segundo Demerval Saviani:

Em suma, o exemplo dos Tupinambá ilustra o entendimento de que numa sociedade sem classes, como era o caso das comunidades primitivas, os fins da educação coincidem com os interesses comuns do grupo $e$ se realizam igualitariamente em todos os seus membros, de modo espontâneo e integral. Ou seja: não havia instituições específicas organizadas tendo em vista atingir os fins da educação. Por isso a educação era espontânea. E cada integrante da tribo assimilava tudo que era possível assimilar, o que configurava uma educação integral. (SAVIANI, 2011, p. 38)

Contra essas maneiras demasiado humanas de manter a história da cultura de povos como os Tupinambá que os jesuítas dispuseram seu plano de controle educativo. Gesto inaugural dessa educação, trouxeram meninos órfãos de Lisboa para a formação do Colégio dos Meninos de Jesus da Bahia, e depois, o Colégio dos Meninos de Jesus de São Vicente, com o intuito de atrair as crian- 
ças indígenas e através delas seus pais, chefes de tribo, para a partir destes converter todo o povoado. Esse período assistiu a um processo de enfraquecimento ontológico da cultura indígena. $\mathrm{O}$ trabalho de Nóbrega $e$ posteriormente, o de Anchieta (com seu teatro), inseria as dualidades cristãs ao mesmo passo que demonizava os elementos da cultura indígena. A Companhia de Jesus possuiu a hegemonia da educação durante os dois primeiros séculos da colonização (XVI, $\mathrm{XVII}$ ), provocando e sedimentando traços profundos na nascente brasilidade. As técnicas educativas jesuítas ficaram conhecidas na história do ensino brasileiro como Pedagogia Clássica; a escola tal como a conhecemos teve seus traços principais (salas de aula, especialização dos saberes, divisão disciplinar, formato técnico, etc.) a partir do projeto jesuíta. Tendo isto como pano de fundo, observemos as possibilidades da atuação profissional em filosofia esboçar novos rumos no ensino brasileiro, através, principalmente, de uma observação sobre o ensino de filosofia em Mossoró-RN.

\section{A filosofia e seu ensino em Mossoró-RN}

Como exemplo do devir histórico educativo focaremos em uma interpretação do ensino de filosofia na cidade de MossoróRN. Diferentemente das demais disciplinas atuais da grade curricular, a filosofia não pode se subsumir, em seu ensino, seja à descrição da sua história, seja pelo ensino dos sistemas filosóficos, ou pela articulação de uma grade temática. Para se fazer jus à sua tradição é necessário que o ensino de filosofia seja já ele mesmo filosófico. "O desafio do professor de filosofia no Brasil hoje, assim, consiste em inventar uma prática de modo que o aprendizado de filosofia faça sentido para os jovens estudantes" (RODRIGO, 2009, p. X). Qualquer que seja a

\footnotetext{
${ }^{4}$ Prefácio ao texto escrito por Sílvio Gallo.
}

metodologia adotada pelo profissional, é indispensável que haja nele uma consciência de sua situação no contexto de sua existência. Só é possível auxiliar um aprendiz em sua autossuperação quando já operamos em nós algo similar. $\mathrm{O}$ engajamento, como esse cuidado (entre o que se faz e o que se diz) é pré-condição para o ensino de filosofia.

Fruto do processo civilizatório, Mossoró reflete os contrastes socioeconômicos provocados por esse devir. Localizada no interior do Rio Grande do Norte (estado em região de relativo baixo desenvolvimento social, historicamente negligenciada), a cidade é um polo comercial da região do oeste do estado. Os professores de filosofia da rede estadual mossoroense de educação são jovens de classe baixa/média-baixa que se (exercitaram em seu estudo durante um mínimo de quatro anos na graduação) dedicam profissionalmente ao ensino de outros jovens em uma situação econômica semelhante ou inferior à sua. Esses professores formados (em sua maioria) pela Universidade do Estado do Rio Grande do Norte possuem a tarefa de lecionar filosofia a um público que não possui quase nenhum aspecto necessário ao exercício do filosofar. Exercício cujo maior empecilho é o analfabetismo funcional. Somando-se a isto a pobreza, a violência, e a marginalidade social como um todo, o desinteresse pela escola (evasão) aparece como uma consequência lógica.

$\mathrm{Na}$ tentativa de desconstruir este ciclo, cabe ao professor a análise rigorosa de seu contexto local. Compreender, não seu alunado como massa, mas apreender a singularidade de seus estudantes em sua existência fática e concreta. Abster-se de seus preconceitos morais para que se transformem e permitam a manifestação própria do modo de ser de seus alunos. É a partir de gestos de compreensão como estes que é possível tocá-los na intimidade de sua consciência: conquistando sua atenção. A obrigatoriedade ou não de um quadro curricular 
conteudista não é nenhum obstáculo nesse processo. É justamente a partir de tais toques, ao ter cativado sua presença, que o professor aprofundará seu trabalho no tratamento dos temas e problemas estabelecidos em seu plano de estudos, modificandoos no mesmo gesto.

Em diálogos informais dois destes professores, sobre seus modos de ensinar filosofia, foi comentado como necessário a análise de problemas que afetem diretamente o estudante, como ponto privilegiado da abordagem filosófica:

O fazer docente se intercala no ser docente, porque, para ser professor você tem a necessidade básica do amor e a transmissão desse saber. Hoje encontramos esse desafio quando entramos jovens na área da educação, pois são vários professores com frustrações e desmotivados. Se deixamos entrar por esse clima sombrio e não usar a reflexão filosófica transmitiremos esse sentimento para sala [...]. Então, na medida do possível, temos que tentar trabalhar o conceito filosófico com a reflexão da realidade

dos estudantes e buscar essa dinamização do pensamento filosófico...

Isto é, a partir de algo tão óbvio que os escapa, de um problema do cotidiano, procura-se compreender com os alunos como isso pôde vir a ser $e$ as alternativas para sua possível superação. Alega o professor: "Existe uma educação muito superficial, na qual os estudantes não veem na escola um lugar de prazer ou alegria, então, na medida do possível a aula de filosofia tende a virar a válvula de escape para esses jovens descreverem seus sentimentos." Trabalhar filosofia desta maneira requer do professor pelo menos pesquisa. No trato da questão da violência na cidade (a exemplo) impõe-se a observação da conjuntura histórica, social, econômica e política que só um movimento in- terdisciplinar pode oferecer. Daí que esses professores manterem vivo diálogo ora com os responsáveis de outras disciplinas, ora com colegas e amigos de formação que se ocupam de outras ciências.

Não é a intenção desses professores formar filósofos (tampouco o é a do curso que os formou), mas permitir o exercício da visão em perspectiva. Aproximar quem aprende daquilo que aprende e, assim, da vida da cultura, chamando a atenção para sua finitude, despertar-lhes novos interesses. Nessa mesma linha, uma jovem professora de filosofia comenta: "O trabalho docente do professor de filosofia é fazer perceber que existe a possibilidade de pensar rigorosamente sobre os problemas, para uma possível compreensão e resolução, para se saber que está vivo (a)." É importante ressaltar que nenhum professor é obrigado a se dedicar desta maneira à docência, como nos expõe a professora: "Viver para diluir o ser humano em indeterminação é o projeto político meu como professora no ensino de filosofia. Há a questão de como fazer cada aluno pegar para si o problema sobre "o que sou?" e iniciar uma queda em si." O que lhe é esperado enquanto profissional é que seus alunos reproduzam os conteúdos em provas e projetos para que consigam boas notas $e$ estas os levem à aprovação em vestibulares, para que após a Universidade se tornem bons profissionais. É exatamente essa contingência, essa não-obrigatoriedade que faz desse engajamento filosófico no trabalho docente uma prática política.

\section{O ensino de filosofia como engajamento político}

Se o ensino de filosofia na maneira acima exemplificada constitui uma prática política, nada garante que toda e qualquer ação docente a seja. No viés pósestruturalista no qual esta pesquisa se emba- 
sa, observamos o conceito de política como descentramento, luta por significações, por compreensões não racionalistas. "Nessa interpretação, toda ação política é uma opção não obrigatória e não necessária em um conjunto de possibilidades imprevistas, a ser considerada contextualmente a cada evento." (LOPES, 2018, p. 85). Logo, o elemento diferencial da atitude política é a não obrigatoriedade, a ser conjecturada no interior de (in)determinado contexto onde se engaja a prática. Ser compelido a algo, obrigado (a), predisposto, é seguir uma norma; é assumir um estado de coisas e reproduzir significados hegemônicos da cultura, em termos nietzschianos: vontade de verdade.

Se observássemos a política de maneira generalizante afirmando que 'tudo é política', eliminaríamos o caráter diferencial do conceito, mas sem essa diferença, esse limite, essa rasura que o separa dos demais, é que o conceito consegue requerer sua particularidade como um significante ${ }^{5}$. Por isso, nem toda docência é uma prática política. Política na apreciação pós-estruturalista é um conceito metafísico (no sentido de que seu significado provém de uma relação com uma tradição) cuja tradução em termos não metafísicos é sempre possível. Política é um significante vazio. Para se fazer enquanto tal tem que ser vazio e produzida por sujeitos que se mostram "pautados por uma falta constitutiva" (LOPES, 2018, p. 84). A luta política se faz então discursivamente na luta pelas significações. O educador que possui seu ethos profissional pautado tão somente na norma, seja de qual natureza for, pode estar trabalhando, mas não estará a fazer política. Mais do que isso: neutralizará a instituição como foco criador de sentidos, possibilidade política. Qualquer discurso que almeje esgotar a significação de política expurga de si a possibilidade de se fazer política. Assim, contingentemente, podemos experimentar vias de

\footnotetext{
${ }^{5}$ Cf. LACLAU, 2011, p. 81 em diante.
}

ação que se distanciem de tais pretensões $e$ exercitar a experiência docente exatamente como experiência em exercício; levantar propostas e provocações ao savoir-faire professoral sobre o vazio significado de seus métodos e produção discursiva; ressignificar, transformar os sentidos, traduzi-los em suma: a luta por significados sempre já é a prática política.

Ensinar filosofia filosoficamente, politicamente, nos coloca como demanda emergencial a atenção rigorosa à linguagem, compreendida aqui não como análise do conjunto de signos e seus significados pela ciência da gramática; mas como o ter ciência que os sentidos dos gestos feitos por nós e o porvir dos acontecimentos estão desde já pautados por uma estrutura de compreensão discursiva que, historicamente, justifica a si própria, autofundamentando-se como norma. Talvez o cuidado com a linguagem, a desconstrução das metafísicas que põem o fino pó da normalidade sobre os acontecimentos históricos que nos afetam, possam permitir a reinterpretação do estado de coisas. Aproximarmo-nos das origens é permitido quando se tem plena consciência de onde se parte. Um professor assim engajado pode esclarecer qual a postura de que parte e os fundamentos (não fundamentados) que a sustenta sem, contudo, ter vontade de verdade, objetivar-se terminantemente nesta escolha.

Quando nos concentramos na postura pós-estruturalista para o desdobramento desta reflexão o fazemos tanto por esta ser uma alternativa à interpretação crítica da educação (predominante no Brasil após os anos 1970) quanto por compreender a contingência das decisões humanas e dos acontecimentos, não suportando nenhuma chancela final nem cristalização conceitual. $\mathrm{O}$ fazer docente do professor de filosofia em Mossoró-RN, enquanto herança das práticas escolares deslanchadas pelo Ratio Studio- 
rum $^{6}$ que atenta pela dependência desta tradição é capaz de perceber em si os limites de sua realização. Dentro de uma perspectiva contextual, as transformações operadas por esquemas como o dos jesuítas se inscrevem no projeto da modernidade de desenvolver a massa como sujeito. As divisões dos alunos em classes, a criação de um espaço fabril para o acolhimento desses alunos, a divisão do conhecimento em áreas e sua aplicação vertical, hierárquica, contribuiu para a formação da brasilidade, orientada por símbolos de comunicação em massa, discursos de pouca consistência e amplo alcance.

A homogeneização das diferenças, a massificação das singularidades que era o projeto de ocidentalização dos indígenas pelos jesuítas continua com força total, sob outras formas:

[...] se observarmos bem, em tais milhões de indivíduos isolados aparecem ao fim e ao cabo mais os traços comuns que os individuais, mesmo que jamais se aglomerem em massa urgente e mesmo que então cada um deles permaneça imbuído pelo sentimento de sua singularidade e de sua distância de todos os outros. Massas que não se reúnem mais efetivamente tendem com o tempo a perder a consciência de sua prática política. (SLOTERDIJK, 2016, p. 22)

Um projeto de massificação dos povos cujo desenvolvimento chamamos de Brasil tem como efeito e motivo o alheamento político desses povos. Afastados dessa prática historicamente, não há espaço para o povo na reinterpretação dos acontecimentos, o que nos lança no locus do hábito e sedimenta a verdade. E a consciência da contingência discursiva, as demandas que as atividades docentes na filosofia nos colocam é a

\footnotetext{
${ }^{6}$ ver: SAVIANI, 2011, p. 49-56.
}

linha de frente desse processo desconstrutivo, interpretativo. De um lado nós jovens professores (as) de filosofia estamos em relação íntima com o mundo científico (e infelizmente ainda positivo) da universidade $e$, por outro, na incultura das mídias de massa e do analfabetismo (funcional e político) de nossos alunos e concidadãos, situação qual ou o nosso trabalho deve ser a transformação, ou não talvez não valha a pena.

\section{Considerações finais}

Esta pesquisa teve por prerrogativa a investigação do problema da cultura, a saber, a questão sobre como articular as exigências técnicas e formação humana no ensino. Começando com uma leitura da Paideia de Jaeger, observamos os conceitos de cultura, formação e história na Antiguidade Grega para contrastá-la com os métodos jesuítas do Brasil colônia que formou o panorama da educação brasílica que se seguiu. O ensino de filosofia, também já configurado na educação da nobreza e alta burguesia pelos padres, distanciou-se do caráter crítico e problemático da própria filosofia em prol das práticas de leitura e escrita do português, e do latim. Hoje, o ensino de uma forma geral e o de filosofia em particular, encontra como dificuldade a intensificação do ensino técnico e da formação científica que cada vez mais nos alija da plena formação humana no sentido da criação de pessoas mais capazes do que nós de cuidar de si próprio, dos outros e do meio.

Como alternativa para se fazer essa transformação, hipotetizamos sobre como articular prática docente em filosofia e engajamento político na cidade de Mossoró-RN. Engajamento como ir além da norma e da requisição, um gesto de responsabilidade no espaço que ordinariamente está fora da nossa alçada. Em diálogo informal com dois professores de filosofia da rede estadual da 
referida cidade, exploramos suas reflexões, aprofundadas pela filosofia pós-estrutural. Como resultado, nos aparece o engajamento político na docência, se não como última possibilidade, ou via correta de ação, pelo menos como oportunidade para criação de sentidos e ressignificações que por um trato mais humano e apropriado com os (as) estudantes propõe a si a responsabilidade de transformar e reler os discursos hegemônicos para fazer surgir a rasura e a diferença. Se o efeito da tradição jesuíta foi o apagamento das diferenças, o surgimento do homemmassa, a história já começa a mudar a partir do professor que advoga para si o seu trabalho como ação política em um terreno indefinidamente hostil.

\section{Referências}

DERRIDA, Jacques. Gramatologia. Campinas: Perspectiva, 2013.

DESCARTES, René. Discurso do Método. São Paulo: Martins Fontes, 1996.

HEIDEGGER, Martin. Ensaios e conferências. Petrópolis: Editora Vozes, 2012.

JAEGER, Werner. Paideia: formação do homem Grego. São Paulo: Martins Fontes, 2013.

LACLAU, Ernesto. Emancipação e Diferença. Rio de Janeiro: Eduerj, 2011.

LOPES, A. C; SISCAR, M. Pensando a política com Derrida: responsabilidade, tradução, porvir. São Paulo: Cortez Editora, 2018.

PERONI, V. M. V.; CAETANO, R. M.; ARELARO, L. R. G. BNCC: Disputa pela qualidade ou submissão da educação? Revista Brasileira de Política e Administração da Educação. n. 1, jan./abr. 2019, p. 035-056.

POPPER, Karl Raimund. A lógica da pesquisa científica. São Paulo: Cultrix, 2013.

RIBEIRO, Darcy. O povo brasileiro: a formação e o sentido do Brasil. São Paulo: Editora

Global, 2015.

RODRIGO, Lidia Maria. Filosofia em sala de aula: teoria e prática para o ensino médio. Campinas: Autores Associados, 2009.

SAVIANI, Demerval. História das ideias pedagógicas no Brasil. Campinas, SP: Autores Associados, 2011.

SLOTERDJIK, Peter. O desprezo das massas: ensaio sobre lutas culturais na sociedade moderna. São Paulo: Estação Liberdade, 2016.

SPENGLER, Oswald. A decadência do Ocidente: esboço de uma morfologia da história universal. Rio de Janeiro: Forense Universitária, 2013. 
Revista Sul-Americana de Filosofia e Educação - RESAFE 